\title{
LOCOMOTOR ATAXIA OF AT LEAST FIVE YEARS' DURATION, WITH LARYNGEAL CRISES, AND CHARCOT'S JOINT-LESION, TERMINA'TING IN GENERAL PARALYSIS OF THE INSANE.
}

\section{BY HENRY HANDFORD, M.D., M.R.C.P., \\ Physician to the General Hospital, Nottingham.}

Largely through the observations of Dr. Savage the association of locomotor ataxia with general paralysis of the insane has been established. It has been recently shown ${ }^{1}$ that not only the cord, but also the sciatic and the peripheral nerves undergo degenerative changes in the vast majority of cases of general paralysis. A few cases evidently commence by a degeneration of the cord, or of the peripheral nerves, or of both; and some authorities consider that most do so. The majority sooner or later develop ataxic symptoms more or less; and in some the ataxia is well marked, while the mental alteration remains somewhat in abeyance. The occurrence of well-marked locomotor ataxia in the middle, or towards the latter part of a case of general paralysis, cannot be said to be altogether infrequent. But it is far from common for general paralysis to supervene upon a typical case of locomotor ataxia of several years' standing. The following is an example of this condition. Unfortunately no post-mortem examination was made, as the friends refused permission, notwithstanding the most strenuous endeavours to obtain their consent.

CASR I.-S. V., aged 28, married, a framework knitter, was admitted into the Nottingham General Hospital under my care in February 1886, crmplaining of difficulty of walking. His father was an insane epileptic, and died in an asvlum. The patient used to bathe a good deal in the Trent, even in winter. No history of syphilis could be obtained. About 3t years ago he began to experience difficulty in walking-and frequently used to fall down. His sight failed, and he had attacks of vomiting, and occasional lozs of control over bladder and rectum. In 1883 he was an inpatient in this hospital, and was diagnosed to be suffering from locomotor ataxia. He then had retention of urine and required

' D'A bando, 'Paralisi Generale Progressiva,' Napoli, 1888; aud 'London Medical Recorder,' 1888. 
the use of a catheter. A few days before his admission on the second occasion, he fell and twisted his right knee, but felt no pain. "He often falls and bruises himself very much, but never feels any pain, and only finds out the bruises from seeing the discoloration of the skin." When I saw him, the knee presented the typical appearance of Charcot's joint lesion, and it remained very much in the same condition till bis death $1 \frac{1}{2}$ jears later. There could be no reasoneble doubt that the joint lesion was started by injury, though, as will be seen later on, there was abundant clinical evidence of peripheral neuritis. On attempting to walk, the movements of the legs were most disorderly. After much oscillation he could at length stand fairly steadily with the eyes open, but fell at once when they were elosed. In the left leg the knee-jerk was quite absent: on the right it could not be tested on account of the swelling of the knee. There was no ankle-clonus. On examining the muscular sense, it was found that he could not place the legs in any desired position, either with the eyes open or closed; and with the eyes closed he could not tell in what position the legs had been placed for him. But on attaching weights to the legs, he could readily detect a difference of $1 \mathrm{lb}$., and in the arms, differences of a few ounces were easily perceired. He could distinguish correctly between a test tube filled with hot water and one filled with cold, both when applied to the legs and the arms. He could nut feel at all a light touch with the finger on the legs. The prick of a pin could sometimes be felt like a touch, but without any pain. In the arms no loss of sensation was deteoted, though he complained that feeling was impaired. About six months before his admission the second time, the arms began to be affected. His hands and fingers, he said, "went dead," and he lost power in them. He frequently dropped things, and in lifting a glass or a cup, always bad to use both hands. The lips, tongne, and pharynx were affected. He spoke very thickly, the lower lip dropped somewbat, and the mouth was slightly drawn to the left. There was loss of sensation in the mouth, so that he could not feel whether any fluid he wished to drink was in his mouth or not, neither could he tell whether the cup was touching his lips. After a short time, by rubbing the lips, \&c., the feeling returned sufficiently to enable him to drink. At the time of his admission there was no muscular atrophy. During his stay in the hospital the gastric crises were marked, but infrequent. There were occasional shooting-pains but no incontinence of urine or feces. While I was examining his throat, on his opening his mouth widely and throwing his head back to enable me to see better, he had a curious epileptoid attack, affecting the muscles of the face, lips, pharynx and larynx. The breathing was interfered with, the face became turgid and dusky, and the whole appearance was alarming. This condition lasted abont half a minuto. He said similar attacks used to come on when he held his head back to be shaved, much to the alarm of the barber. Sometimes the attacks last several minutes, and he falls, if standing at the time. $\mathrm{He}$ loses consciousness, and 
remembers nothing of what happens while he is in the attacks. When these epileptoid attacks could be avoided the vocal cords were seen very readily. During quiet respiration the left cord was further from the middle line than the right, and its border was concave, showing some paralysis of the inner fibres of the thyro-ary tmoid muscle. Both cords moved during phonation, but the left less freely than the right. He had some difficulty in swallowing solid food, and had to drink with each mouthful to enable him to swallow it. The tongue was protruded to the left and the face was drawn to the left during articulation and during the epileptoid attacks. Taste was tested with quinine, salt and sugär. It was very deficient, but not absent. Common sensation in the tongue was much diminished. The power of smell was sluggish. There was partial ptosis of the left eye. Sight was imperfect. The pupils were unequal : the right was dilated to the size of a No. 10 catheter, and the left was about the size of a No. 6. They did not react to the strong light of a mirror, and it was doubtful if they moved at all with accommodation. The disce were grey, and the connective tissue stroma was too plainly visible. He slept badly and was low-spirited. He said that for ten months past he had occasionally, especially after reading or thinking, suddenly lost his memory and power of attention. "He wants to do or say something, but cannot tell what it is." If he had been reading, he did not know what he had been reading about, and could not understand what he continued to read, and had to stop. In about a quarter of an hour he was all right again. After a few weeks he left the hospital and went to live with his mother and a married sister, but he was so quarrelsome that the sister left, and he remained alone with his mother. He had some kind of fit or congestive attack, and shortly after this, began to grow excited and sleepless, and used to sit up all night. Though in receipt of parish relief he took a new house, began to drive about in cabs, and buy all sorts of things he could not pay for. He told his relations he was going to take them to a big house in the country, where he was going to build a lot of factories. He drove, up to my house in a cab and said his mother had a lot of money, and had started a line of omnibuses. He himself had plenty of money, and he wanted to be a private patient. He was very anxious to have all his teeth out, as he thought he could eat better with an artificial set. He persisted in this desire for several months. His teeth were remarkably good and sound, and never showed that tendency to fall out, which is sometimes observed in cases of locomotor ataxia. Next day he drove up to the hospital and told them I had advised him to have his leg off, and to have a cork one instead, and he wanted that done. After this he was removed to the Borough Asylum, and for the further notes I am indebted to the kindness of Mr. Evan Powell. The notes say: " He was admitted on Sept. 15th, 1886, with unmistakable signs. of general paralysis. He was emotional, and occasionally burst out into tears without apparent cause. He had total loss of sensation in both feet and legs up to the middle of the thighs 
Sensation was also lost in both hands and arms, nearly up to the shonlders, where he could only just feel the priok of a pin. The mouth was drawn to the left: there was ptosis of the left eyelid, and tremor in the facial and lingual muscles. Sept. 26th.Epileptiform fit. Oct. 24th.-Hallucinations of sight and hearing. Paralysis of the soft palate causes much difficulty of swallowing. Mfay 9th, 1887.-Has delusions that people he cannot see are pulling at his arms and legs. He died on July 4th, after being in the asylum 10 months.

Shortly after this case, I was examining the larynx of an epileptic woman, and as soon as she opened wide ber mouth and threw back her head, she had an epileptoid attack, much resembling the one described in the earlier part of this paper. There was marked strabismus, at first conjugate to the left, and then convergent; the tongue was moved rapidly from side to side, and respiration ceased, and she became partially unconscious. She attempted to vomit, and then slowly recovered. The whole attack lasted two or three minutes. Subsequent attempts to examine the throat produced slighter attacks, more of a cataleptic nature. Eventually, by making her breathe deeply and rapidly, a good view of the cords was obtained, and a paralysis of the left cord was found. This explained a condition of partial aphonia which had come on suddenly a few days previously. The paralysis passed off in a short time, and its cause was not discovered.

The phenomena in these two cases were very similar. They appear to have been epileptiform attacks, originating in irritation of the laryngeal nerves. Long ago it was shown experimentally in the lower animals that irritation of a sensory nerve could produce an epileptic seizure. It is said that cases which appear to commence as ataxy, and change to general paralysis, should be looked upon as examples of the co-existence of the two affections, and the dominance of the symptoms of one or the other. As this patient had wellmarked ataxy four and a half years before his death, it is difficult to suppose he had general paralysis at that time, as the course of the disease in that case would have been very slow; whereas when once mental symptoms were developed, death followed within a year, indicating a rather rapid course. When first seen, a year and a half before his death, he had no mental alienation whatever, except some depression, which was not unnatural in his unfortunate condition. The only signs at all suggestive of general paralysis were the epileptoid attacks, the inequality of the pupils, the facial paralysis, and the thickness of speech. The first was in some measure accounted for by heredity, as his father was an insane epileptic. Inequality of 
the pupils is occasionally found in locomotor ataxy. The thickness of speech was sufficiently accounted for by the paralysis, and the impaired sensation in the tongue and lips. The characteristic tremor of the lips and tongue was absent at this time. I should mention that he early had some mental depression, but that did not at first suggest to me the oncoming of general paralysis ; for I have long been accustomed to associate some appreciable degree of mental change with the majority of cases of chronic cord degeneration. It is natural that a disabling disease, not necessarily associated with much or any pain, should lead to a despondent view of things. But the mental aspect of patients with cord-degenerations is verv different from that of the most hopeless, and, perhaps, equally painless, but always cheerful, cases of phthisis ; and equally different from the sad resignation of malignant disease. The mental aspect in cases of cord degenerations has seemed to me to tend towards melancholia, with discontent and quarrelsome dissatisfaction. Though tabes dorsalis is said to commence most frequently in the lumbar region of the cord, the early occurrence of ptosis and of atrophy of the disc, indicates an implication of the cranial nerves, or medulla and basal ganglia, or all three in the degenerative process. It is reasonable therefore to infer, that of the same, or similar, character to the system degeneration in the cord, there is a degradation of that perfect state of nutrition of the cerebrum as a whole (we do not know what portion, if any, is the organ of mind), which is necessary for "mens sana in corpore sano," though it may not proceed so far as to be readily demonstrable by the microscope. 